\title{
Reducing the global burden of sepsis: a positive legacy for the COVID-19 pandemic?
}

\author{
The European Society of Intensive Care Medicine (ESICM), The Global Sepsis Alliance (GSA)* and The Society of \\ Critical Care Medicine (SCCM)
}

(c) 2021 The Author(s)

The emergence of the SARS-CoV-2 virus in December 2019 and the subsequent coronavirus disease 2019 (COVID-19) pandemic has presented the world with the most serious health threat in living memory. The resultant pandemic has caused millions of deaths and unprecedented social and economic disruption. The response to the pandemic has also been unprecedented; countries have closed their borders, some have instituted draconian but effective public health measures, and the global scientific community has come together to produce robust research evidence and novel vaccines in record time. Mass vaccination programs are now underway, and while it is too early to know clearly their effectiveness in ending the pandemic, we can hope that this marks the beginning of the end.

The pandemic has put intensive care units, ventilators, vaccines, corticosteroids, and immunotherapies into the headlines of print and television news and all forms of digital and social media. The progress in response to COVID-19 stands in stark contrast to that of intensive care practitioners' signature condition, namely sepsis. Sepsis, defined as "life-threatening organ dysfunction caused by a dysregulated host response to infection" [1], is an umbrella term describing the clinical syndrome which can arise from infections caused by bacteria, viruses, fungi, and other micro-organisms. Recently, estimates for global, regional, and national sepsis incidence and mortality were published by the Global Burden of Disease Study [2]. In 2017, sepsis was estimated to affect

\footnotetext{
${ }^{*}$ Correspondence: konrad.reinhart@charite.de Department of Anaesthesiology and Operative Intensive Care Medicine Charité Universitätsmedizin Berlin, Germany
}

The members of the writing committee from the European Society of Intensive Care (ESICM) and Global Sepsis Alliance (GSA) and Society of Critical Care Medicine (SCCM) are listed in the acknowledgement section. close to 50 million people and to cause or contribute to 11 million deaths, with over 3 million of those deaths being in children or adolescents [2]. Despite these harrowing statistics, decades of scientific enquiry, and literally billions of euros spent on clinical trials, there are currently no specific treatments effective for sepsis in general. Current efforts to reduce the global burden of sepsis are focused on improving public and healthcare worker awareness to avoid delays in diagnosis and treatment, and rapid treatment using appropriate antibiotics and bundles of supportive care focused on the common bacterial causes of sepsis [3].

Patients critically ill with COVID-19 satisfy the diagnostic criteria for sepsis and exhibit a phenotype and pathology with both similarities and differences to that of sepsis caused by other pathogens. Patients with severe COVID-19 suffer from multi-organ dysfunction, including acute respiratory distress syndrome (ARDS), vasodilatory shock, acute kidney injury, coagulation, brain, heart, and gastrointestinal dysfunction, representing the common manifestations that characterise sepsis. In fact, management guidelines for COVID-19 have been directly developed from similar sepsis guidelines [4].

COVID-19-induced sepsis also has features that appear unique. While children may develop multi-system inflammatory syndrome [5], they rarely suffer from severe COVID-19 in marked contrast to other forms of sepsis that result in the deaths of over 3 million children each year. Childhood deaths from sepsis occur mainly in low and middle-income countries, particularly in sub-Saharan Africa, and many are due to sepsis in relation to respiratory infections and diarrhoeal diseases [2]. SARS-CoV-2 overwhelmingly causes sepsis from respiratory infections whereas, although respiratory infections are the commonest cause of fatal non-COVID sepsis,

\section{实


infections at other sites cause a substantial proportion of non-COVID sepsis [2]. Other features differentiating COVID-19 include direct viral toxicity [6], pulmonary vascular injury, and a more marked hypercoagulable state [7]. The identification of these features has been made possible by the intense study of millions of cases of sepsis caused by this one unique and readily identifiable pathogen. Similar differentiating features may exist in subsets of patients with sepsis due to other individual pathogens that have not been subject to the same intense investigation, and which are not readily apparent in studies of heterogeneous populations infected with a wide variety of sepsis-inducing microorganisms. Another feature of COVID-19 to attract attention is the prolonged morbidity beyond the acute illness that has been termed "long COVID" [8]. This occurs not only in those who have been critically ill but is also reported in patients with much milder disease. That patients who survive other forms of sepsis suffer similar longer term ill effects is not well recognised [9]. Recent studies demonstrate up to $50 \%$ of sepsis survivors will suffer from a post-sepsis syndrome characterized by persisting physical, cognitive and psychological sequelae [9]. This ongoing morbidity represents an important but poorly quantified component of the global burden of sepsis.

In the absence of specific effective treatments, supportive therapies for organ dysfunction remain the mainstay of the treatment of non-COVID sepsis, and uncertainty remains about the safety and efficacy of many widely used adjunctive treatments. In contrast, the global research effort encompassing basic science and laboratory investigation together with rapidly-recruiting clinical trials has already provided robust evidence for and against the use of specific treatments for COVID-related sepsis. The demonstrated benefit of corticosteroids in reducing mortality from COVID-19 $[10,11]$. stands in stark contrast to the investigation of corticosteroids to treat non-COVID Sepsis where more than five decades of research and at least 40 clinical trials have resulted in equivocal evidence of their effectiveness [12].

There are clear, understandable, and justifiable reasons for the global response to COVID-19 being much greater than that for endemic sepsis. The virus is easily and rapidly transmissible causing many millions of cases and deaths in a short period of time. This has the potential to overwhelm health care systems and to cause unprecedented societal and economic disruption. Nevertheless, looking toward the control of the pandemic is the appropriate time to consider how the response to the pandemic can inform efforts to substantially reduce the current and future global burden of sepsis. One of the most important aspects of COVID-19 has been the rapid generation of reliable evidence by platform trials, such as REMAP-CAP [13] as well as new clinical outcomes targets developed by the WHO [14]. Broad acceptance of these newer trial designs and outcome targets has facilitated research in COVID-19 that may also be applied in sepsis research.

The COVID-19 pandemic has dramatically illustrated the crucial role of policymakers in enacting public health regulations to control the spread of the virus, this success depends not only on close collaboration between clinicians but also on effective public messaging to achieve compliance. Public health measures targeted at preventing infection, notably vaccination and the provision of clean water and hygienic health care have the potential to dramatically reduce the burden of sepsis, particularly maternal sepsis and sepsis in children in low and middle-income countries. Additionally, policymakers actively supporting the embedding of clinical research into routine care, notably in the United Kingdom [15], has been crucial in generating public trust and engagement in clinical research. These are all recommended actions of the 2017 World Health Assembly resolution on improving the prevention, diagnosis, and clinical management of sepsis [16].

Similar to cancer, sepsis is a valuable overall term that could become recognizable to the public. Also similar to cancer, sepsis will benefit from more precise molecular definitions and identifying phenotypes more likely to respond to new therapeutics.

Recognising that sepsis results from a dysregulated host response to infection and the failure of prior research efforts to identify specific treatments, the research infrastructure, notably international adaptive platform trials, set up or adapted to rapidly investigate treatments for COVID-19 should be maintained and supported beyond the end of the pandemic. With an estimated 50 million cases of sepsis occurring each year, including even a small proportion of affected patients in such trials would allow us to determine which patients and which forms of sepsis are amenable to treatment with immunomodulators and other treatments, and to investigate how to prevent and treat the longer-term health effects of sepsis. 
Planning for post-pandemic sepsis research and policy should start now. Reducing the global burden of sepsis, particularly in resource-poor settings, would be a fitting legacy for the tragedy of this global pandemic.

Specific actions based on the pandemic that will reduce the global burden of sepsis:

\footnotetext{
Recognition that sepsis, like cancer, is a valuable umbrella term describing a heterogeneous syndrome with a core underlying mechanism; a dysregulated immune response to infection

Recognition that sepsis caused by different pathogens and in different populations may respond to different treatment approaches

Fostering the understanding that increasing awareness of sepsis, education of the public and health care professionals on the prevention, early recognition, the need to manage sepsis as an emergency, and good training in supportive care will reduce sepsis mortality from all causes

Maintaining political and policymaker focus on public health measures that can reduce the global burden of sepsis and by following the requests of the WHO sepsis resolution to integrate sepsis in the national health strategies of all member states

Supporting with research funding and infrastructure to better understand the overall burden of sepsis and to characterize the heterogeneity of sepsis caused by different organisms in different populations and expanding the capacity of international platform trials embedded in routine clinical care
}

\section{Acknowledgements}

Members of the Writing Committee: M. M. Levy: Division of Pulmonary/Critical Care Medicine, Warren Alpert Medical School at Brown University, Providence, RI, USA; S. Finfer: The George Institute for Global Health, University of New South Wales, Sydney, NSW, Australia, School of Public Health, Imperial College, London, UK; F. Machado: Intensive Care Sector at the Department of Anesthesiology, Pain and Intensive Care at Federal University of Sao Paulo, Brazil, Latin America Sepsis Institute; L. Kaplan: Perelman School of Medicine, University of Pennsylvania Division of Trauma, Surgical Critical Care, Emergency Surgery Philadelphia, PA, USA; J. Kesecioglu: Department of Intensive Care Medicine, University Medical Center Utrecht, Utrecht University, The Netherlands; A Rhodes: Adult Critical Care, St George's University Hospitals NHS Foundation Trust, St George's University of London, UK; R. Daniels: Critical Care Department, University Hospitals Birmingham NHS Foundation Trust, UK; N. Kissoon: Acute and Critical Care, Department of Pediatrics, University of British Columbia and British Columbia Children's Hospital, Vancouver, Canada; E. Nsutebu: Infectious Diseases Division, Sheikh Shakhbout Medical City, Abu Dhabi, UAE L. A. Gorordo: Adults Intensive Care Unit, Hospital Juárez de México, México City, México; I. Malik: Department of Critical Care, University of Texas, Anderson Cancer Center, Houston, Texas, USA; A. Alhawsawi: Saudi Central Board for Accreditation of Health Institutions (CBAHI), Riyadh, Saudi Arabia; M. Cecconi: Humanitas clinical and research center-IRCCS, Rozzano (Milano) Italy, Humanitas University, Department of Biomedical Sciences, Pieve Emanuele, Milano, Italy; E. Giamarellos: 4th Department of Internal Medicine, National and Kapodistrian University of Athens, Medical School, Greece; G. Martin: Division of Pulmonary, Allergy, Critical Care and Sleep Medicine \& Emory University School of Medicine, Atlanta, Georgia USA; L. Schlapbach: Child Health Research Centre, The University of Quensland, Paediatric Intensive Care Unit, Queensland Children's Hospital, Brisbane, Australia, Pediatric and Neonatal Intensive Care Unit, Children's Research Center, University Children's Hospital Zurich, Zurich, Switzerland; K. Reinhart: Department of Anaesthesiology and Operative Intensive Care Medicine (CCM, CVK), Charité Universitätsmedizin Berlin, Germany, Corporate Member of Freie Universität Berlin, HumboldtUniversität zu Berlin, Germany

M. M. Levy and S. Finfer contributed equally to the writing of this article.

\section{Funding}

Open Access funding enabled and organized by Projekt DEAL.

\section{Declarations}

\section{Conflicts of interest}

Mitchell Levy, Simon Finfer, Flavia Machado, Lewis Kaplan, Jozef Kesecioglu, Ron Daniels, Niranjan Kissoon, Emmanuel Nsutebu, Imrana Malik, Abdulelah Alhawsawi, Greg Martin, and Luregn Schlapbach declare that they have no competing interests. Gorordo-Delsol AL - LAG-D reports personal fees from Pfizer de México SA de CV, personal fees from Merck Sharp \& Dohme S de RL de CV, personal fees from Abbott Laboratories de México SA de CV, all outside the submitted work; Global Sepsis Alliance Executive Committee Member. Evangelos Giamarellos-Bourboulis - has received honoraria from Abbott $\mathrm{CH}$, Angelini Italy, InflaRx GmbH, MSD Greece, XBiotech Inc., and B.R.A.H.M.S $\mathrm{GmbH}$ (Thermo Fisher Scientific); independent educational grants from AbbVie Inc, Abbott CH, Astellas Pharma Europe, AxisShield, bioMérieux Inc, Novartis, InflaRx GmbH, and XBiotech Inc; and funding from the FrameWork 7 program HemoSpec (granted to the National and Kapodistrian University of Athens), the Horizon2020 Marie-Curie Project European Sepsis Academy (granted to the National and Kapodistrian University of Athens), and the Horizon 2020 European Grant ImmunoSep (granted to the Hellenic Institute for the Study of Sepsis). Maurizio Cecconi - Member of surviving sepsis campaign executive committee, ESICM President Elect (may be President when this is accepted), panel member WHO Guidance on Drugs for COVID19, consulting fees for Edwards Lifesciences and Directed Systems Konrad Reinhart - Was unpaid President of the Global Sepsis Alliance until November 2012 and is shareholder of InflaRx NV a Jena/Germany based Biotech Company that evaluates an immune-modulatory approach for the adjunctive treatment of COVID-19. Andrew Rhodes - Co-chair of the Surviving Sepsis Campaign (SSC).

\section{Open Access}

This article is licensed under a Creative Commons Attribution-NonCommercial 4.0 International License, which permits any non-commercial use, sharing, adaptation, distribution and reproduction in any medium or format, as long as you give appropriate credit to the original author(s) and the source, provide a link to the Creative Commons licence, and indicate if changes were made. The images or other third party material in this article are included in the article's Creative Commons licence, unless indicated otherwise in a credit line to the material. If material is not included in the article's Creative Commons licence and your intended use is not permitted by statutory regulation or exceeds the permitted use, you will need to obtain permission directly from the copyright holder. To view a copy of this licence, visit http://creativecommons.org/licen ses/by-nc/4.0/.

\section{Publisher's Note}

Springer Nature remains neutral with regard to jurisdictional claims in published maps and institutional affiliations.

Received: 4 December 2020 Accepted: 9 April 2021

Published online: 16 June 2021

\section{References}

1. Singer $M$, Deutschman CS, Seymour CW, Shankar-Hari M, Annane D, Bauer M, Bellomo R, Bernard GR, Chiche JD, Coopersmith CM (2016) The third international consensus definitions for sepsis and septic shock (sepsis-3). JAMA 315(8):801-810

2. Rudd KE, Johnson SC, Agesa KM, Shackelford KA, Tsoi D, Kievlan DR Colombara DV, Ikuta KS, Kissoon N, Finfer S et al (2020) Global, regional, and national sepsis incidence and mortality, 1990-2017: analysis for the Global Burden of Disease Study. Lancet 395(10219):200-211

3. Rhodes A, Evans LE, Alhazzani W, Levy MM, Antonelli M, Ferrer R, Kumar A, Sevransky JE, Sprung CL, Nunnally ME et al (2017) Surviving sepsis campaign: international guidelines for management of sepsis and septic shock: 2016. Crit Care Med 45(3):486-552

4. Alhazzani W, Møller MH, Arabi YM, Loeb M, Gong MN, Fan E, Oczkowski S, Levy MM, Derde L, Dzierba A et al (2020) Surviving sepsis campaign: guidelines on the management of critically ill adults with Coronavirus Disease 2019 (COVID-19). Crit Care Med 48(6):e440-e469

5. Nakra NA, Blumberg DA, Herrera-Guerra A, Lakshminrusimha S (2020) Multi-System Inflammatory Syndrome in Children (MIS-C) following 
SARS-CoV-2 infection: review of clinical presentation, hypothetical pathogenesis, and proposed management. Children (Basel) 7(7):69. https://doi. org/10.3390/children7070069

6. Gupta A, Madhavan MV, Sehgal K, Nair N, Mahajan S, Sehrawat TS, Bikdeli B, Ahluwalia N, Ausiello JC, Wan EY et al (2020) Extrapulmonary manifestations of COVID-19. Nat Med 26(7):1017-1032

7. Loo J, Spittle DA, Newnham M (2021) COVID-19, immunothrombosis and venous thromboembolism: biological mechanisms. Thorax. https://doi. org/10.1136/thoraxjnl-2020-216243

8. The L (2020) Facing up to long COVID. Lancet 396(10266):1861

9. Prescott HC, Iwashyna TJ, Blackwood B, Calandra T, Chlan LL, Choong K, Connolly B, Dark P, Ferrucci L, Finfer S et al (2019) Understanding and enhancing sepsis survivorship. Priorities for research and practice. Am J Respir Crit Care Med 200(8):972-981

10. RECOVERY (2020) Dexamethasone in hospitalized patients with Covid-19. N Engl J Med 384(8):693-704

11. Sterne JAC, Murthy S, Diaz JV, Slutsky AS, Villar J, Angus DC, Annane D, Azevedo LCP, Berwanger O, Cavalcanti AB et al (2020) Association between administration of systemic corticosteroids and mortality among critically ill patients with COVID-19: a meta-analysis. JAMA 324(13):1330-1341
12. Rygård SL, Butler E, Granholm A, Møller MH, Cohen J, Finfer S, Perner A, Myburgh J, Venkatesh B, Delaney A (2018) Low-dose corticosteroids for adult patients with septic shock: a systematic review with meta-analysis and trial sequential analysis. Intensive Care Med 44(7):1003-1016

13. Angus DC, Berry S, Lewis RJ, Al-Beidh F, Arabi Y, van Bentum-Puijk W, Bhimani Z, Bonten M, Broglio K, Brunkhorst F et al (2020) The REMAP-CAP (Randomized Embedded Multifactorial Adaptive Platform for Community-acquired Pneumonia) Study. Rationale and design. Ann Am Thorac Soc 17(7):879-891

14. Docherty AB, Harrison EM, Green CA, Hardwick HE, Pius R, Norman L, Holden KA, Read JM, Dondelinger F, Carson G et al (2020) Features of 20 133 UK patients in hospital with COVID-19 using the ISARIC WHO Clinical Characterisation Protocol: prospective observational cohort study. BMJ 369:m19885

15. Angus DC, Gordon AC, Bauchner H (2021) Emerging lessons from COVID19 for the US clinical research enterprise. JAMA 325(12):1159-1161. https://doi.org/10.1001/jama.2021.3284

16. Reinhart K, Daniels R, Kissoon N, Machado FR, Schachter RD, Finfer S (2017) Recognizing sepsis as a global health priority-a WHO resolution. N Engl J Med 377(5):414-417 